\title{
Anticipated Partner Infidelity and Men's Intimate Partner Violence: The Mediating Role of Anxiety
}

\author{
Steven Arnocky \\ Nipissing University \\ Wendy Gomes \\ Nipissing University
}

\author{
Shafik Sunderani \\ University of Toronto OISE \\ Tracy Vaillancourt \\ University of Ottawa
}

\begin{abstract}
Anxiety is believed to have evolved, in part, as a signal of threats to survival or reproductive fitness. In a sample of 66 heterosexual undergraduate men who were currently in exclusive romantic relationships, we explored whether symptoms of anxiety mediated links between anticipated partner infidelity and men's intimate partner violence. Results indicated that symptoms of anxiety mediated relationships between anticipated partner infidelity and physical aggression, partner injury, psychological aggression, and sexual aggression toward a partner. Results are discussed in terms of the evolution of anxiety as an emotion that mediates reaction to adaptive threats.
\end{abstract}

Keywords: intimate partner violence (IPV), mate-retention, anxiety, mating, power, infidelity

Infidelity has been observed across diverse human cultures (Buss, 1996) and is a leading cause of divorce worldwide (Betzig, 1989). Global estimates of nonpaternity resulting from infidelity range between $1.7 \%$ and $29.8 \%$ (Anderson, 2006), suggesting that genetic cuckoldry persists in contemporary human society. Due to cryptic ovulation and the internal fertilization processes of human reproduction, men's genetic relatedness to offspring is uncertain. For men, a partner's sexual infidelity increases the risk of him unwittingly investing time and resources toward another man's offspring (Symons, 1979). A man's reproductive fitness therefore relies, in part, upon his ability to anticipate, prevent, and respond to an intimate

This article was published Online First August 25, 2014.

Steven Arnocky, Department of Psychology, Nipissing University; Shafik Sunderani, Department of Applied Psychology \& Human Development, University of Toronto OISE; Wendy Gomes, Department of Psychology, Nipissing University; Tracy Vaillancourt, Faculty of Education and School of Psychology, University of Ottawa.

Correspondence concerning this article should be addressed to Steven Arnocky, Department of Psychology, Nipissing University, 100 College Drive, North Bay, ON, P1B 8L7, Canada. E-mail: stevena@nipissingu.ca partner's sexual infidelity (Buss \& Duntley, 2011; Miner, Starratt, \& Shackelford, 2009; Peters, Shackelford, \& Buss, 2002; Starratt, Shackelford, Goetz, \& McKibbin, 2007).

It has been argued that the feelings of worry, apprehension, and physiological hyperarousal, which characterize anxiety (Barlow, 2002), may have evolved to identify adaptive challenges in men and women alike (Buss, 1990; Hofer, 1995; Hofmann, Moscovitch, \& Heinrichs, 2002; Marks \& Nesse, 1994; Price, 2003; Stein \& Bouwer, 1997). Researchers have suggested that real (Gordon, Baucom, \& Snyder, 2004) and imagined infidelity can elicit, among other emotions, an anxiety response (e.g., Maner, 2009; Shackelford, LeBlanc, \& Drass, 2000). In addition, studies examining physiological arousal levels have corroborated with selfreport methods showing increased arousal in response to an infidelity threat. For example, Buss and colleagues (1992) asked men to imagine their partner committing a sexual infidelity. The researchers found that men exhibited increased physiological distress as measured via heart-rate and galvanic skin response. Compared to controls, participants in the experimental condition had accelerated heart rates. More- 
over, researchers suggest that the degree of anxiety felt after a partner's infidelity may be influenced by one's own mate-value. For instance, Phillips (2010) found that low levels of perceived mate-value were associated with increased levels of insecurity and anxiety in response to infidelity.

Anxiety is considered a fundamental component of sexually jealousy and aggressive behavior toward romantic partners (Buss, 2003/1994; Buunk, 1997), whereby the "threat of losing one's mate to a rival evokes jealousy that includes not only anxiety but also seeking of reassurance and aggression to try to avert loss" (Marks \& Nesse, 1994 p. 252). Indeed, emotions are known to influence both cognition and behavior (Clore, Schwarz, \& Conway, 1994) and may be vital for motivating responses to various adaptive challenges (see Arnocky, Sunderani, Miller, \& Vaillancourt, 2012; Maner et al., 2005). Baumeister and Tice (1990), for instance, characterize anxiety as having evolved to facilitate survival and reproductive success via the maintenance of social relationships. In particular, they argue that anxiety promotes corrective or alternative actions in the face of exclusion from a social group or relationshipthis includes the threatened loss of a romantic partner (see Buss, 1990). From this perspective, experiences of anxiety following a real or imagined infidelity correspond with an evolutionary theory of emotion (Cosmides \& Tooby, 2000; Haselton \& Ketelaar, 2006; Tooby \& Cosmides, 1990). In the present study, we empirically test the hypothesis of anxiety as a mediator of relationships between men's perceptions of their partner's infidelity risk and aggression toward the romantic partner (physical aggression and injury, psychological aggression, and sexual aggression).

\section{Infidelity and IPV}

One disconcerting behavioral response to a perceived risk, suspicion, or occurrence of infidelity is men's perpetration of intimate partner violence (IPV), which can constitute physical, psychological, or sexual aggression. It has been well documented that real or perceived infidelity may be one precipitating factor in the perpetration of intimate partner violence (see Daly \& Wilson, 1988, for a review). Physical aggression in response to infidelity may serve specific purposes, such as to (a) punish the partner for her infidelity, (b) discourage the partner from future infidelities or from relationship defection, and/or (c) signal to rivals that one is capable of violence, which may deter potential mate poachers (see Buss, 2005). Similarly, psychological aggression may be employed to reduce a partner's self-esteem and further control or dominate that partner (e.g., Buss, 2003/1994). Alternatively, aggression toward an intimate partner may exist as a general behavioral response to (or byproduct of) anger meant to recalibrate unfavorable welfare tradeoff ratios (see Sell, Tooby, \& Cosmides, 2009).

Sexual coercion has also been linked to infidelity. For instance, Goetz and Shackelford (2006) found a positive association between men's perception of their partner's infidelity and both mate-retention behavior and rape (see also Starratt, Goetz, Shackelford, McKibbin, \& Stewart-Williams, 2008). In an earlier study, Shields and Hanneke (1983) collected reports from battered wives who were physically and/or sexually abused within their relationship. Women were asked, "Have you ever had sex with someone other than your husband while living with your husband?" Women who reported they had engaged in an affair were more likely to have experienced rape, as well as both physical abuse and rape (combined), compared to women who had not engaged in infidelity. Sexual coercion (i.e., forcible rape and/or manipulation to coerce the partner into having sex) may serve to dominate and control one's partner (similar to physical and psychological aggression) or to prevent cuckoldry via sperm competition by introducing sperm in his partner's reproductive tract (e.g., Goetz \& Shackelford, 2006), or perhaps via semen displacement (Gallup et al., 2003). To date, no research has examined whether feelings of anxiety mediate relations between anticipated partner infidelity and IPV.

\section{Anxiety and Aggression}

Anxiety has been linked to aggressive behavior in mammals, including humans (Allen \& Allen, 1975; Berkowitz, 1974; Rule \& Nesdale, 1976). Anxiety [or an anxiety-like response in nonhumans] is associated with activity of the hypothalamic-pituitary-adrenal axis (Allen \& Allen, 1975). Activation of this "fight or flight" 
system consists of increased heart rate and greater secretion of stress-hormones such as corticotropin releasing factor, which, in, turn can lead to various adaptive behavioral outputs such as vigilance, freezing, avoidance, and aggression (Marks \& Nesse, 1994). Increases in cortisol levels have also been linked with more vigilant mate-guarding behavior among males of certain species (e.g., Insel, Wang, \& Ferris, 1994). For instance, Surbeck and colleagues (2012) suggest that glucocorticoid secretion observed in male bonobos ( $P$ an paniscus) may result from proximity with females who are in oestrous as well as from an anticipated aggressive interaction. In men, high levels of cortisol have been linked to reactive aggression (van Bokhoven et al., 2005).

Converging lines of evidence suggest that subjective experiences of anxiety may be linked to aggressive behavior. Among youth, anxiety is related to a host of externalizing disorders such as oppositional defiant disorder and conduct disorder (Marmorstein, 2007), as well as to the persistence of aggressive behavior over time (Ialongo, Edelsohn, Werthamer-Larsson, Crockett, \& Kellam, 1996). Neumann, Veenema, and Beiderbeck (2010), in their review of the literature on anxiety and aggression, argued that "excessive aggression and violence likely develop as a consequence of generally disturbed emotional regulation, such as abnormally high or low levels of anxiety" (p. 1). Aggression has been linked to emotional distress consisting of depression, anger, and anxiety symptoms (Tschann, Flores, Pasch, \& VanOss Marin, 2005). Some researchers suggest aggression is an avenue in which anxious individuals behaviorally display their fears. For instance, Kashani, Deuser, and Reid (1991) reported in a study of over 200 17-year-olds that anxiety was significantly higher in both verbally and physically aggressive participants. More recently, researchers have shown that men with higher levels of anxiety also exhibit more relationally aggressive behavior (Marsee, Weems, \& Taylor, 2008). Anxiety has also been found to correlate with both the physical and verbal aggression, hostility, and anger subscales of the Buss-Perry Aggression Questionnaire (BPAQ-SF; Diamond \& Magaletta, 2006). Recent research has replicated these findings experimentally. Nederlof, Murdis, and Hovens (2014) induced various mood states (happy, neutral, anx- ious, or angry) in participants. Results showed that participants in either the angry or anxious mood state displayed more aggressive attitude compared to those randomly assigned to the neutral condition. In the present study, we expected that anxiety would mediate the relationship between anticipated partner infidelity and aggression directed at that partner: physical aggression (Hypothesis 1), partner injury (Hypothesis 2), sexual aggression (Hypothesis 3), and psychological aggression (Hypothesis 4).

\section{Method}

\section{Participants}

Sixty-six participants were recruited via posters and stations placed in common areas around the campus of a midsized Canadian university. A priori sample size calculation with an expected medium effect size (Cohen's $f^{2}$ ) of .25, power of .80 , and $p<.05$ yielded a minimum sample of 42 participants. Our final sample consisted of 66 heterosexual undergraduate university men between the ages of 18 and 28 years who were currently in romantic relationships $\left(M_{\text {age }}=22, S D=3.2\right)$. The ethnic composition of the sample was as follows: White (60\%), Arab (9\%), Southeast Asian (5\%), Black (4\%), South Asian (3\%), Latin American (3\%), Asian $(1 \%)$, and unidentified/other (15\%). Participants received \$20 (Canadian dollars) remuneration for their time.

\section{Measures}

Anxiety. Participants completed the anxiety subscale from the Depression, Anxiety, and Stress Scales (Lovibond \& Lovibond, 1995). The subscale consists of seven items that assess autonomic arousal, skeletal muscle effects, situational anxiety, and subjective experiences of anxious affect occurring over the past week. The anxiety subscale consists of the following items: "I was aware of dryness of my mouth," "I experienced breathing difficulty," "I experienced trembling," "I was worried about situations in which I might panic and make a fool of myself," "I felt I was close to panic," "I was aware of the action of my heart in the absence of physical exertion," "I felt scared without any good reason." The measure employs a 4-point scale anchored 
$0=$ did not apply to me at all and $3=$ applied to me very much, or most of the time. Studies of the psychometric properties of the Depression, Anxiety, and Stress Scales suggest that each subscale comprises a specific orthogonal factor (Henry \& Crawford, 2005). The anxiety subscale seems to be a valid indicator of increased hypothalamic-pituitary-adrenal axis activity (Singh et al., 2012). The DASS (full version) has also shown good test-retest reliability (e.g., Akin \& Çetin, 2007). In the present study, the measure showed acceptable internal consistency $(\alpha=.71)$.

Aggression toward an intimate partner. The Conflict Tactics Scale (Aggression subscales) consists of 39 self-report items measuring the frequency with which individuals perpetrate various acts of aggression toward their romantic partner. Of interest to the present study were the assessments of (a) physical assault, (b) partner injury, (c) sexual coercion, and (d) psychological aggression (Straus, Hamby, Boney-McCoy, \& Sugarman, 1996). Following Straus and Gelles (1986), we were interested in severe acts, which are defined as acts that have a relatively high probability of causing harm (see Straus et al., 1996). Responses on these subscales can vary between never, once, twice, 3 to 5 times, 6 to 10 times, and more than 10 times in the past 12 months. In the present study, each aggression subscale was internally consistent: psychological aggression $(\alpha=.76)$, physical assault $(\alpha=$ $.82)$, sexual coercion, $(\alpha=.86)$, and physical injury $(\alpha=.97)$.

Anticipated partner infidelity. We employed a measure of anticipated partner infidelity developed by Goetz and Causey (2009). The measure consists of the following two items: (a) "How likely do you think it is that your current partner will, in the future, have sexual intercourse with someone other than you, while in a relationship with you?" and (b) "Please indicate your agreement or disagreement with the following statement: 'My partner will probably be sexually unfaithful to me in the future." Participants responded using a 7-point Likert-type scale anchored at $1=$ not at all likely/completely disagree and $7=$ extremely likely/completely agree. The two items comprising the measure were significantly correlated at the bivariate level, $r=.392, p<.001$, and were averaged to create a composite.

\section{Results}

\section{Analytic Approach}

A mediating variable is one that helps to account for an observed relationship between a predictor variable and a criterion variable (Baron \& Kenny, 1986). In the present study, we expected symptoms of anxiety to mediate links between anticipated partner infidelity and various types of aggression. To examine our hypothesis, we employed bootstrapping mediation analyses using 1,000 bootstrapping samples per equation. Bootstrapping is superior to traditional techniques for exploring mediated relationships because it does not enforce assumptions of normally distributed data. Some researchers suggest bootstrapping might also provide increased power and reduced type-I error (MacKinnon, Lockwood, Hoffman, West, \& Sheets, 2002). We utilized the INDIRECT macro developed for SPSS by Preacher and Hayes (2008). Descriptive statistics are presented in Table 1.

Hypothesis 1: Partner infidelity, anxiety, and physical assault.

To test our mediation hypotheses, we first had to determine whether there was a predictive link between our independent variable and our mediator. To this end, we found that anticipated partner infidelity did indeed predict anxiety symptoms $(b=1.43, p=.001)$. Next, the hypothesis that anticipated partner infidelity would predict more frequent physical assault was examined. Results showed that anticipated

Table 1

Descriptive Statistics

\begin{tabular}{lcccccr}
\hline & $N$ & $M$ & $S D$ & Min. & Max. & Range \\
\hline 1. Partner infidelity & 66 & 2.22 & 1.55 & 1.50 & 8.00 & 6.50 \\
2. Anxiety & 66 & 4.76 & 4.74 & 0.00 & 22.00 & 22.00 \\
3. Age & 66 & 22.0 & 3.20 & 18.00 & 28.00 & 10.00 \\
4. Physical aggression & 66 & - & - & 0.00 & 45.00 & 45.00 \\
5. Partner Injury & 66 & - & - & 0.00 & 26.00 & 26.00 \\
6. Sexual aggression & 66 & - & - & 0.00 & 35.00 & 35.00 \\
$\begin{array}{l}\text { 7. Psychological } \\
\quad \text { aggression }\end{array}$ & 66 & - & - & 0.00 & 35.00 & 35.00 \\
\hline
\end{tabular}


partner infidelity had a total effect on physical assault toward romantic partners of $(b=1.48$, $p=.045)$. However, when we included anxiety in the model we found that the direct effect of anticipated partner infidelity upon physical assault was reduced $(b=0.62, n s)$. Anxiety significantly predicted physical assault toward one's romantic partner $(b=0.67, p=.010)$. Anxiety fully mediated (i.e., reduced to nonstatistical significance) the link between anticipated partner infidelity and physical assault (bootstrapping: 95\% LL $=0.08,95 \% \mathrm{UL}=$ 3.80) supporting H1. The mediation model contributed .10 toward explained variance $\left(R^{2}\right.$ adj).

Hypothesis 2: Partner infidelity, anxiety, and partner injury.

The hypothesis that anticipated partner infidelity would predict partner injury was examined (Hypothesis 2). We found that anticipated partner infidelity had a total effect on partner injury of ( $b=2.01, p=.001)$. However, when we included anxiety in the model, we found that the direct effect of anxiety on partner injury was reduced $(b=1.50, p=.004)$. Anxiety significantly predicted partner injury $(b=0.40, p=$ $.03)$. Anxiety partially mediated the link between anticipated partner infidelity and partner injury (bootstrapping: 95\% LL $=0.00,95 \%$ $\mathrm{UL}=0.46)$ supporting Hypothesis 2 . The mediation model contributed .22 toward explained variance $\left(R^{2} \mathrm{adj}\right)$.

Hypothesis 3: Partner infidelity, anxiety, and sexual coercion.

The hypothesis that anticipated partner infidelity would predict more frequent sexual coercion toward her was examined (Hypothesis 3). We found that anticipated partner infidelity had a total effect on sexual coercion toward romantic partners of $(b=1.10, p=.001)$. However, when we included anxiety in the model, we found that the direct effect of anticipated partner infidelity on sexual coercion was reduced $(b=$ $0.83, p=.005)$. Anxiety had a statistically significant effect on sexual coercion toward one's romantic partner $(b=0.22, p=.034)$. Moreover, anxiety partially mediated (i.e., $c^{\prime}$ remains statistically significant) the link between anticipated partner infidelity and sexual coercion (bootstrapping: 95\% LL $=0.01,95 \%$ $\mathrm{UL}=1.31$ ), supporting Hypothesis 3 . The me- diation model contributed .21 toward explained variance $\left(R^{2} \mathrm{adj}\right)$.

Hypothesis 4: Partner infidelity, anxiety, and psychological aggression.

The hypothesis that anticipated partner infidelity would predict more frequent psychological aggression toward her was examined (Hypothesis 4). We found that anticipated partner infidelity had a total effect on psychological aggression toward romantic partners of $(b=$ $1.44, p=.001)$. However, when we included anxiety in the model we found that the direct effect of anticipated partner infidelity upon psychological aggression was reduced $(b=1.00$, $p=.020)$. Anxiety significantly predicted psychological aggression toward one's romantic partner $(b=0.34, p=.019)$. Anxiety partially mediated the link between anticipated partner infidelity and physical aggression (bootstrapping: $95 \% \mathrm{LL}=0.003,95 \% \mathrm{UL}=1.75)$ supporting Hypothesis 4 (see Figure 1). The mediation model contributed .26 toward explained variance $\left(R^{2}\right.$ adj).

\section{General Discussion}

Emotions organize cognition and behavior to resolve adaptive challenges (Cosmides \& Tooby, 2000; Haselton \& Ketelaar, 2006; Tooby \& Cosmides, 1990). Our findings within the present studies support the hypothesis that men's experiences of anxiety mediate links between anticipated partner infidelity and IPV. Specifically, we showed that participants who anticipated a greater likelihood of their partner committing an infidelity simultaneously exhibited greater levels of anxiety that predicted four different components of IPV - physical aggression, partner injury, sexual aggression, and psychological aggression. Taken together, these findings suggest that anxiety is elevated in men who anticipate a partner's infidelity; these men are more likely to victimize their intimate partners. Victimization of one's intimate partner may serve a mate-retention function, as outlined by Goetz et al. (2008), to (a) deter one's partner from subsequent sexual defection through punishment, and/or (b) to contest threats of another men's sperm fertilizing an intimate partner's egg (in the case of sexual coercion).

Why would anxiety mediate the relationship between anticipated partner infidelity and ag- 


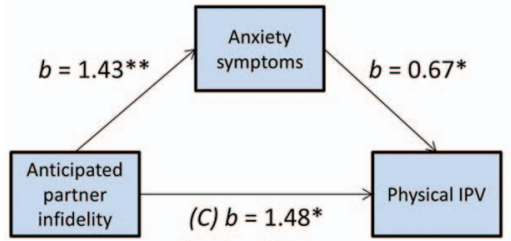

(C') $b=0.62$ n.s.

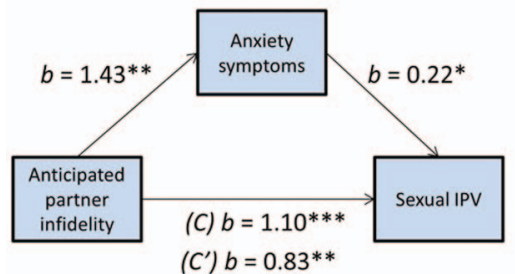

$\left(C^{\prime}\right) b=0.83^{* *}$

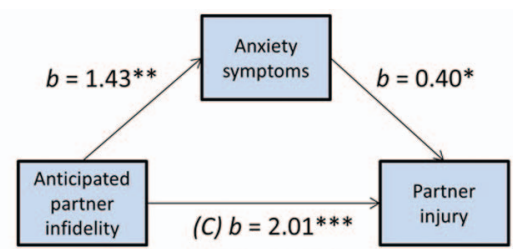

$\left(C^{\prime}\right) b=1.50^{* *}$

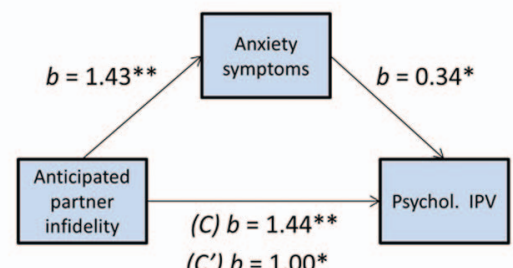

$\left(C^{\prime}\right) b=1.00^{*}$

Figure 1. The mediating role of anxiety on the relationships between anticipated partner infidelity and physical IPV, partner injury, sexual IPV, and psychological IPV. IPV = intimate partner violence. ${ }^{*} p<.05 .{ }^{* *} p<.01$. ${ }^{* * * *} p<.001$. See the online article for the color version of this figure.

gressive behavior? Anxiety is a domain-general emotion that can apply to many domain-specific processes. Mating and sine qua non reproductive success is an area that is central to the human mind; emotions and cognitive mechanisms have likely coevolved, or been otherwise co-opted in part, to sensitize one to cues of infidelity (e.g., Maner, 2009; Maner, Miller, Rouby, \& Galliot, 2009). Cuckoldry bears a significant number of costs for men. These costs include (a) misallocation of resources invested away from one's own offspring, (b) squandered time and effort invested in attracting and maintaining an unfaithful partner, (c) lost mating opportunities taken away from attracting and maintaining other prospective partners, (d) reputational damage incurred upon discovery of others within the same social network, and (e) resources provided to promote their rival's children, in addition to being misdirected toward one's own offspring (see Buss, 2005). Accordingly, emotions such as anxiety may have evolved to serve as an internal compass to inspire behavioral action in response to a real or perceived adaptive threat (Cosmides \& Tooby, 2000; Maner, 2009).

Anxiety is an emotion that is universal to many sexually reproducing species, and one that is highly sensitized to attending to threats within the environment (see Maner, Gailliot, Rouby, \& Miller, 2007). Based on previous work showing that anxious jealousy is particularly important and prevalent when exposed to reproductive threats (Barelds \& BareldsDijkstra, 2007), the present study sought to examine the role of anxiety as a more basic and ubiquitous subcomponent of mammalian survival and reproduction. We draw an analogous comparison between the function of emotional anxiety and the sensation of pain in response to a physical injury. For example, Nesse and Williams (1994) suggest that the evolutionary function of physical pain serves as a "red flag" or a "smoke alarm" to signal to the organism that attention and efforts need to be directed to the source of pain that compromises survival (see also Broom, 2001). In a parallel fashion, we suspect that anxiety in the context of anticipated partner infidelity directs attention to the threat during a period of a compromised mating circumstance, perhaps signaling to the individual to select a course of action from the assortment of possible response strategies: one of which involves violence directed toward their partner. Previous studies have shown that intimate partner violence is predicted by men's affective states, including low self-esteem (Burke et al., 1988) and sexual jealousy (Frieze, 1983). 
Yet there are specific costs associated with the perpetration of partner-directed violence. A perpetrator may garner reputational damage as an "abuser" within their mating pool, which can detract from their potential to secure alternative mates at a future time point. Another cost of perpetrating partner-directed violence is the risk of retaliation from their partner or their partner's kin and social network (i.e., family members and cross-sex friends). Finally, a perpetrator of partner-directed violence may risk mate desertion if the victimized partner perceives the benefits of staying in the relationship do not outweigh the costs of searching for a partner who is nonviolent (See Buss, 2005). In spite of these costs, the drawbacks of inflicting violence onto a romantic partner might be mitigated after assessing the benefits of adopting an in-pair aggressive strategy. The benefits gained from partner-directed violence for the perpetrator could potentially include: circumventing potential and/or subsequent infidelity, decreasing the uncertainty of paternity, increasing the probability of mate retention, restoring reputational damage, and improving overall reproductive success (see Figueredo \& McCloskey, 1993; Wilson \& Daly, 1993).

\section{Limitations and Future Directions}

The generalizability of the findings from the present study was limited by the explicit focus on men as perpetrators of partner violence. However, it is becoming increasingly clear that women can also benefit from mating competition (e.g., Arnocky, Sunderani, \& Vaillancourt, 2013; Sunderani, Arnocky, \& Vaillancourt, 2013), including the perpetration of aggression (Arnocky \& Vaillancourt, 2012; Arnocky et al., 2012; Vaillancourt, 2005; Vaillancourt, Miller, \& Sharma, 2010), and that men may face unique and debilitating challenges when exposed to partner violence (Arnocky \& Vaillancourt, in press). Future research may seek to examine whether anxiety plays a similar role in mediating mate-retention processes among women.

Another limitation in the present study is that relationship duration and commitment level were not controlled for. It is possible that the greater the relational investment, in terms of time, emotional, or financial commitment, the more threatening or distressing the anticipated infidelity may be perceived. Future research would benefit from exploring whether relationship duration and commitment moderate the relationship between anticipated infidelity and IPV. Our use of self-perceived anxiety over the last week, though a reliable and valid measure of anxiety symptoms, is not an ideal measure of relationship threat anxiety. Future research should consider the use of a measure of emotional response to a specific relationship threat situation (such as when confronted with an attractive mate-poacher; Arnocky, Ribout, Mirza, \& Knack, 2014).

Future studies could also benefit from exploring the unique contribution of the basic emotions of anxiety, anger, and sadness as a response implicated in anticipated partner infidelity and its link to men's partner-violence. In the present study, we focused solely on anxiety; however, emotions experienced in relation with anticipated partner infidelity are likely much more diverse and multifaceted. The emotion of sadness and anger (i.e., the other basic subcomponents of jealousy) along with hostility and sadness may all serve a distinguishable function to promote unique behavioral action as well. Or it may be the case that subjective feelings of anger, sadness, hostility, and anxiety would work together in a concerted effort, all part of a broader affective experience to the individual, to promote partner-directed violence as one distinct subtype within the constellation of mate-retention behaviors available for use. Future research might also benefit from exploring whether men with higher base-rate anxiety are especially prone to aggression following anticipated partner infidelity. Experimental research could assess base-rate anxiety and then have participants imagine a hypothetical infidelity scenario, followed by measures of real or intended aggression toward a sexual rival or toward the partner (using for instance, a pointsubtraction task).

Goetz and Shackelford (2006) speculate that some men may engage in IPV in response to real, perceived, or anticipated partner infidelity. However, the sequence of events remains unclear. It may be the case that a partner's infidelity increases the likelihood of male perpetrated partner-directed violence. Alternatively, there may exist a reciprocal influence between men's perceptions of infidelity and partnerdirected violence, insofar as the more violent the man is in the intimate dyad, the more likely 
the women will leave the relationship or to commit an infidelity. Future studies may wish to disentangle the directionality of this causal chain of events and/or empirically confirm the bidirectional nature of this dynamic. Future research might address these causality concerns by priming males with thoughts of infidelity, and subsequently measure indices of anxiety (e.g., self-report or physiological, such as galvanic skin response), as well as attitudes toward mate-retention and partner violence. Future research might also seek to test whether intimate partner violence is indeed an effective mate retention strategy that deters partners from defecting within the relationship. Ultimately, gaining a better understanding of the social and emotional variables associated with IPV might aid intervention strategies. For instance, the benefits of anxiety management and reduction strategies may be of substantial importance to the prevention and treatment of IPV.

\section{Conclusion}

The present research provides evidence to support the role of anxiety in mediating the relationship between men's anticipation of their partner's infidelity and their use of physical, psychological, and sexual aggression directed toward their partner. Anxiety may serve to draw attention to such threats to the romantic relationship and promote compensatory actions in response to such real or perceived threats.

\section{References}

Akin, A., \& Çetin, B. (2007). Depression anxiety and stress scale (DASS): The study of validity and reliability. Educational Sciences: Theory \& Practice, 7, 260-268.

Allen, J. P., \& Allen, C. F. (1975). Amygdala participation in tonic ACTH secretion in the rat. Neuroendocrinology, 19, 115-125. doi:10.1159/ 000122432

Anderson, K. G. (2006). How well does paternity confidence match actual paternity? Current Anthropology, 47, 513-520. doi:10.1086/504167

Arnocky, S., Ribout, A., Mirza, R., \& Knack, J. M. (2014). Perceived mate availability influences intrasexual competition, jealousy and mate guarding behavior. Journal of Evolutionary Psychology, 12, 45-64. doi:10.1556/JEP.12.2014.1.3

Arnocky, S., Sunderani, S., Miller, J., \& Vaillancourt, T. (2012). Jealousy mediates the relationship be- tween attractiveness comparison and females' indirect aggression. Personal Relationships, 19, 290303. doi:10.1111/j.1475-6811.2011.01362.x

Arnocky, S., Sunderani, S., \& Vaillancourt, T. (2013). Mate poaching and mating success in humans. Journal of Evolutionary Psychology, 11, 65-83. doi:10.1556/JEP.11.2013.2.2

Arnocky, S., \& Vaillancourt, T. (2012). A multiinformant longitudinal study on the relationship between aggression, peer victimization, and adolescent dating status. Evolutionary Psychology, 10, 253-270.

Arnocky, S., \& Vaillancourt, T. (in press). Sex differences in response to victimization by an intimate partner: More stigmatization and less helpseeking among males. Journal of Aggression, Maltreatment, \& Trauma. doi:10.1080/10926771 .2014 .933465

Barelds, D. P. H., \& Barelds-Dijkstra, P. (2007). Love at first sight or friends first? Ties among partner personality trait similarity, relationship onset, relationship quality, and love. Journal of Social and Personal Relationships, 24, 479-496. doi:10.1177/0265407507079235

Barlow, D. H. (2002). Anxiety and its disorders: The nature and treatment of anxiety and panic (2nd ed.). New York, NY: Guilford Press.

Baron, R. M., \& Kenny, D. (1986). The moderatormediator variable distinction in social psychological research: Conceptual, strategic, and statistical considerations. Journal of Personality and Social Psychology, 51, 1173-1182. doi:10.1037/00223514.51.6.1173

Baumeister, R. F., \& Tice, D. M. (1990). Anxiety and social exclusion. Journal of Social and Clinical Psychology, 9, 165-195. doi:10.1521/jscp.1990.9 .2 .165

Berkowitz, L. (1974). Some determinants of impulsive aggression: Role of mediated associations with reinforcements for aggression. Psychological Review, 81, 165-176. doi:10.1037/h0036094

Betzig, L. (1989). Causes of conjugal dissolution: A cross-cultural study. Current Anthropology, 30, 654-676. doi:10.1086/203798

Broom, D. M. (2001). Evolution of pain. In E. J. L. Lord Soulsby \& D. Morton (Eds.), Pain: Its nature and management in man and animals. Royal Society of Medicine International Congress Symposium Series (Vol. 246, pp. 17-25). London, UK: Royal Society of Medicine.

Burke, P. J., Stets, J. E., \& Pirog-Good, M. A. (1988). Gender identity, self-esteem, and physical and sexual abuse in dating relationships. Social Psychology Quarterly, 51, 272-285. doi:10.2307/2786925

Buss, D. M. (1990). The evolution of anxiety and social exclusion. Journal of Social and Clinical Psychology, 9, 196-201. doi:10.1521/jscp.1990.9 .2 .196 
Buss, D. M. (1996). Paternity uncertainty and the complex repertoire of human mating strategies. American Psychologist, 51, 161-162. doi:10.1037/ 0003-066X.51.2.161

Buss, D. M. (2003). The evolution of desire: Strategies of human mating. New York, NY: Basic Books. (Original work published 1994)

Buss, D. M. (2005). The murderer next door: Why the mind is designed to kill. New York, NY: Penguin Press.

Buss, D. M., \& Duntley, J. D. (2011). The evolution of intimate partner violence. Aggression and Violent Behavior, 16, 411-419. doi:10.1016/j.avb .2011.04.015

Buss, D. M., Larsen, R. J., Westen, D., \& Semmelroth, J. (1992). Sex differences in jealousy: Evolution, physiology and psychology. Psychological Science, 3, 251-255. doi:10.1111/j.1467-9280 .1992.tb00038.x

Buunk, B. P. (1997). Personality, birth order, and attachment styles as related to various types of jealousy. Personality and Individual Differences, 23, 997-1006. doi:10.1016/S01918869(97)00136-0

Clore, G. L., Schwarz, N., \& Conway, M. (1994). Affective causes and consequences of social information processing. In R. S. Wyer \& T. K. Srull (Eds.), Handbook of social cognition (pp. 323417). Hillsdale, NJ: Erlbaum.

Cosmides, L., \& Tooby, J. (2000). Evolutionary psychology and the emotions. In M. Lewis \& J. M. Haviland-Jones (Eds.), Handbook of Emotions, 2nd Edition (pp. 91-115.) New York, NY: Guilford Press.

Daly, M., \& Wilson, M. (1988). Homicide. New York, NY: Aldine.

Diamond, P. M., \& Magaletta, P. R. (2006). The Short-Form Buss-Perry Aggression Questionnaire (BPAQ-SF): A validation study with federal offenders. Assessment, 13, 227-240. doi:10.1177/ 1073191106287666

Figueredo, A. J., \& McCloskey, L. A. (1993). Sex, money, and paternity: The evolution of domestic violence. Ethology \& Sociobiology, 14, 353-379. doi:10.1016/0162-3095(93)90024-C

Frieze, I. H. (1983). Investigating the causes and consequences of marital rape. Signs, 8, 532-553. doi: $10.1086 / 493988$

Gallup Jr., G. G., Burch, R. L., Zappieri, M. L., Parvez, R. A., Stockwell, M. L., \& Davis, J. A. (2003). The human penis as a semen displacement device. Evolution and Human Behavior, 24, $277-$ 289. doi:10.1016/S1090-5138(03)00016-3

Goetz, A. T., \& Causey, K. (2009). Sex differences in perceptions of infidelity: Men often assume the worst. Evolutionary Psychology, 7, 253-263.

Goetz, A. T., \& Shackelford, T. K. (2006). Sexual coercion and forced in-pair copulation as sperm competition tactics in humans. Human Nature, 17, 265-282. doi:10.1007/s12110-006-1009-8

Goetz, A. T., Shackelford, T. K., Romero, G. A., Kaighobadi., F., \& Minder, E. J. (2008). Punishment, proprietariness, and paternity: Men's violence against women from an evolutionary perspective. Aggression and Violent Behavior, 13, 481-489. doi:10.1016/j.avb.2008.07.004

Gordon, K. C., Baucom, D. H., \& Snyder, D. K. (2004). An integrative intervention for promoting recovery from extramarital affairs. Journal of Marital and Family Therapy, 30, 213-231. doi: 10.1111/j.1752-0606.2004.tb01235.x

Haselton, M. G., \& Ketelaar, T. (2006). Irrational emotions or emotional wisdom? The evolutionary psychology of emotions and behavior. In J. P. Forgas (Ed.), Hearts and minds: Affective influences on social cognition and behavior (pp. 2140). New York, NY: Psychology Press.

Henry, J. D., \& Crawford, J. R. (2005). The shortform version of the Depression Anxiety Stress Scales (DASS-21): Construct validity and normative data in a large non-clinical sample. British Journal of Clinical Psychology, 44, 227-239. doi: 10.1348/014466505X29657

Hofer, M. A. (1995). An evolutionary perspective on anxiety. In S. P. Roose \& R. A. Glick (Eds.), Anxiety as symptom and signal (pp. 17-38). Hillsdale, NJ: Analytic Press.

Hofmann, S. G., Moscovitch, D. A., \& Heinrichs, N. (2002). Evolutionary mechanisms of fear and anxiety. Journal of Cognitive Psychotherapy, 16, 317330. doi:10.1891/jcop.16.3.317.52519

Ialongo, N., Edelsohn, G., Werthamer-Larsson, L., Crockett, L., \& Kellam, S. (1996). The course of aggression in first-grade children with and without comorbid anxious symptoms. Journal of Abnormal Child Psychology, 24, 445-456. doi:10.1007/ BF01441567

Insel, T. R., Wang, Z., \& Ferris, C. F. (1994). Patterns of brain vasopressin receptor distribution associated with social organization in microtine rodents. The Journal of Neuroscience, 14, 5381-5392.

Kashani, J. H., Deuser, W., \& Reid, J. C. (1991). Aggression and anxiety: A new look at an old notion. Journal of the American Academy of Child \& Adolescent Psychiatry, 30, 218-223. doi: 10.1097/00004583-199103000-00009

Lovibond, S. H., \& Lovibond, P. F. (1995). Manual for the depression anxiety stress scales. Sydney, Australia: Psychology Foundation.

MacKinnon, D. P., Lockwood, C. M., Hoffman, J. M., West, S. G., \& Sheets, V. (2002). A comparison of methods to test mediation and other intervening variable effects. Psychological Methods, 7, 83-104. doi:10.1037/1082-989X.7.1.83 
Maner, J. K. (2009). Anxiety: Proximate processes and ultimate functions. Social and Personality Psychology Compass, 3, 798-811. doi:10.1111/j .1751-9004.2009.00211.x

Maner, J. K., Gailliot, M. T., Rouby, D. A., \& Miller, S. L. (2007). Can't take my eyes off you: Attentional adhesion to mates and rivals. Journal of Personality and Social Psychology, 93, 389-401. doi:10.1037/0022-3514.93.3.389

Maner, J. K., Kenrick, D. T., Becker, V., Robertson, T. E., Hofer, B., Neuberg, S. L., . . . Schaller, M. (2005). Functional projection: How fundamental social motives can bias interpersonal perception. Journal of Personality and Social Psychology, 88, 63-78. doi:10.1037/0022-3514.88.1.63

Maner, J. K., Miller, S. L., Rouby, A., \& Galliot, M. T. (2009). Intrasexual vigilance: The implicit cognition of romantic rivalry. Journal of Personality and Social Psychology, 97, 74-87. doi: 10.1037/a0014055

Marks, I. F. M., \& Nesse, R. M. (1994). Fear and fitness: An evolutionary analysis of anxiety disorders. Ethology \& Sociobiology, 15(5-6), 247-261. doi:10.1016/0162-3095(94)90002-7

Marmorstein, N. R. (2007). Relationships between anxiety and externalizing disorders in youth: The influences of age and gender. Journal of Anxiety Disorders, 21, 420-432. doi:10.1016/j.janxdis .2006.06.004

Marsee, M. A., Weems, C. F., \& Taylor, L. K. (2008). Exploring the association between aggression and anxiety in youth: A look at aggressive subtypes, gender, and social cognition. Journal of Child and Family Studies, 17, 154-168. doi: 10.1007/s10826-007-9154-1

Miner, E. J., Starratt, V. G., \& Shackelford, T. K. (2009). It's not all about her: Men's mate value and mate retention. Personality and Individual Differences, 47, 214-218. doi:10.1016/j.paid.2009 .03 .002

Nederlof, A. F., Murdis, P., \& Hovens, J. E. (2014). Anger, anxiety, and feelings of delusional threat as predictors of aggressive attitudes: An experimental mood induction study in a non-clinical sample. Personality and Individual Differences, 57, 25-30. doi:10.1016/j.paid.2013.09.006

Nesse, R. M., \& Williams, G. C. (1994). Why we get sick: The new science of Darwinian medicine. New York: Vintage Books.

Neumann, I. D., Veenema, A. H., \& Beiderbeck, D. I. (2010). Aggression and anxiety: Social context and neurobiological links. Frontiers in Behavioral Neuroscience, 4, . doi:10.3389/fnbeh.2010.00012

Peters, J., Shackelford, T. K., \& Buss, D. M. (2002). Understanding domestic violence against women: Using evolutionary psychology to extend the feminist functional analysis. Violence and Victims, 17, 255-264. doi:10.1891/vivi.17.2.255.33644
Phillips, A. (2010). Indignation or insecurity: The influence of mate value on distress in response to infidelity. Evolutionary Psychology, 8, 736-750.

Preacher, K. J., \& Hayes, A. F. (2008). Asymptotic and resampling strategies for assessing and comparing indirect effects in multiple mediator models. Behavior Research Methods, 40, 879-891. doi:10.3758/BRM.40.3.879

Price, J. S. (2003). Evolutionary aspects of anxiety disorders. Dialogues in Clinical Neuroscience, 5, 223-233. doi:10.1016/B978-0-323-03354-1.50022-5

Rule, B. G., \& Nesdale, A. R. (1976). Emotional arousal and aggressive behavior. Psychological Bulletin, 83, 851-863. doi:10.1037/0033-2909.83 .5 .851

Sell, A., Tooby, J., \& Cosmides, L. (2009). Formidability and the logic of human anger. Proceedings of the National Academy of Sciences, USA, 106, 15073-15078. doi:10.1073/pnas.0904312106

Shackelford, T. K., LeBlanc, G. J., \& Drass, E. (2000). Emotional reactions to infidelity. Cognition and Emotion, 14, 643-659. doi:10.1080/ 02699930050117657

Shields, N. M., \& Hanneke, C. R. (1983). Battered wives' reactions to marital rape. In D. Finkelhor, R. J. Gelles, G. T. Hotaling, \& M. A. Straus (Eds.), The dark side of families: Current family violence research (pp. 131-148). Thousand Oaks, CA: Sage.

Singh, R., Goyal, M., Tiwari, S., Ghildiyal, A., Nattu, S. M., \& Das, S. (2012). Effects of examination stress on mood, performance and cortisol levels in medical students. Indian Journal of Physiology and Pharmacology, 56, 48-55.

Starratt, V. G., Goetz, A. T., Shackelford, T. K., McKibbin, W. F., \& Stewart-Williams, S. (2008). Men's partner-directed insults and sexual coercion in intimate relationships. Journal of Family Violence, 23, 315-323. doi:10.1007/s10896-0089153-z

Starratt, V. G., Shackelford, T. K., Goetz, A. T., \& McKibbin, W. F. (2007). Male mate retention behaviours vary with risk of partner infidelity and sperm competition. Acta Psychologica Sinica, 39, 523-527.

Stein, D. J., \& Bouwer, C. (1997). A neuroevolutionary approach to the anxiety disorders. Journal of Anxiety Disorders, 11, 409-429. doi: 10.1016/S0887-6185(97)00019-4

Straus, M. A., \& Gelles, R. J. (1986). Societal change and change in family violence from 1975 to 1985 as revealed by two national surveys. Journal of Marriage and the Family, 48, 465-479. doi: $10.2307 / 352033$

Straus, M. A., Hamby, S. L., Boney-McCoy, S., \& Sugarman, D. B. (1996). The revised Conflict Tactics Scales (CTS2): Development and preliminary 
psychometric data. Journal of Family Issues, 17, 283-316. doi:10.1177/019251396017003001

Sunderani, S., Arnocky, S., \& Vaillancourt, T. (2013). Individual differences in mate poaching: An examination of hormonal, dispositional, and behavioral mate-value traits. Archives of Sexual Behavior, 42, 533-542. doi:10.1007/s10508-0129974-y

Surbeck, M., Deschner, T., Weltring, A., \& Hohmann, G. (2012). Social correlates of variation in urinary cortisol in wild male bonobos (Pan paniscus). Hormones and Behavior, 62, 27-35. doi: 10.1016/j.yhbeh.2012.04.013

Symons, D. (1979). The evolution of human sexuality. New York: Oxford University Press.

Tooby, J., \& Cosmides, L. (1990). The past explains the present: Emotional adaptations and the structure of ancestral environments, Ethology \& Sociobiology, 11, 375-424. doi:10.1016/ 0162-3095(90)90017-Z

Tschann, J. M., Flores, E., Pasch, L. A., \& VanOss Marin, B. (2005). Emotional distress, alcohol use, and peer violence among Mexican-American and European-American adolescents. Journal of Adolescent Health, 37, 11-18. doi:10.1016/j.jadohealth.2004.07.009
Vaillancourt, T. (2005). Indirect aggression among humans: Social construct or evolutionary adaptation? In R. E. Tremblay, W. H. Hartup, \& J. Archer (Eds.), Developmental origins of aggression (pp. 158-177). New York, NY: Guilford Press.

Vaillancourt, T., Miller, J., \& Sharma, A. (2010). "Tripping the Prom Queen": Female intrasexual competition and indirect aggression. In K. Osterman (Ed.), Indirect and direct aggression (pp. 17-32). Frankfurt, Germany: Peter Lang Publishing.

van Bokhoven, I., Van Goozen, S. H. M., van Engeland, H., Schaal, B., Arseneault, L., Séguin, J. R., . . Tremblay, R. E. (2005). Salivary cortisol and aggression in a population-based longitudinal study of adolescent males. Journal of Neural Transmission, 112, 1083-1096. doi:10.1007/ s00702-004-0253-5

Wilson, M., \& Daly, M. (1993). An evolutionary psychological perspective on male sexual proprietariness and violence against wives. Violence and Victims, 8, 271-294.

Received January 11, 2014

Revision received March 30, 2014 Accepted July 24, 2014

\section{E-Mail Notification of Your Latest Issue Online!}

Would you like to know when the next issue of your favorite APA journal will be available online? This service is now available to you. Sign up at http://notify.apa.org/ and you will be notified by e-mail when issues of interest to you become available! 